\title{
Hydration behaviour of synthetic saponite at variable relative humidity
}

\author{
KARMOUS MOHAMED SALAH* and JEAN LOUIS ROBERT ${ }^{\dagger}$ \\ Département de physique, faculté des sciences de Bizerte, 7021 Zarzouna, Tunisia \\ ${ }^{\dagger}$ IMPMC Campus Boucicaut, 140 rue de Lourmel, 75015 Paris, France
}

MS received 13 December 2010; revised 21 January 2011

\begin{abstract}
Hydration behaviour of synthetic saponite was examined by X-ray powder diffraction simulation at various relative humidities (RH). The basal spacing of the Ca-saponite increased stepwise with increase in RH. The $(00 l)$ reflections observed reflect single or dual hydration states of smectite. Quasi-rational, intermediate, or asymmetrical reflections were observed for all XRD patterns and reflecting heterogeneity of the samples, especially along the transition between two hydration states.
\end{abstract}

Keywords. Hydration; saponite; XRD; simulation; RH.

\section{Introduction}

Smectites are 2:1 layered clays, each layer consisting of one sheet of octahedra between two sheets of silicon tetrahedra. Saponite is a trioctahedral smectites with all the octahedral positions occupied by divalent cations, generally $\mathrm{Mg}(\mathrm{II})$. Isomorphic substitutions with cations of lower oxidation state may occur in both sheets, producing a negatively charged layer, which is balanced by interlayer hydrated cations (Güven 1988; Karmous et al 2006, 2007). The moderate charge of the layers allows water molecules to penetrate the interlayer space and hydrate the interlayer cations, which results in a swelling of the crystal structure.

The swelling of smectites is complex (Laird 2006). The hydration of expandable 2:1 phylosilicates has been extensively studied for over 50 years. Early work (Mooney et al 1952 ) demonstrated that smectite hydration is strongly influenced by $\mathrm{H}_{2} \mathrm{O}$ vapour pressure $\left(p / p_{0}\right)$, the extent of crystalline swelling, and the nature of the exchangeable cations. Recently, using XRD simulation, Karmous et al (2009) studied the influence of charge location on the hydration properties of synthetic saponite and hectorite under relative humidity, Ferrage et al (2010) demonstrated the hydration heterogeneity of different synthetic saponites with low and high charge and investigated about the ideal position of water molecule in the interlayer space.

This paper reports characterization of hydration properties of synthetic saponite exchanged with $\mathrm{Ca}$ cation.

\section{Materials and methods}

Synthetic saponite was prepared by hydrothermal synthesis in Morey-type externally heated pressure vessels (Karmous et al 2009). The started synthetic material has a structural formulae:

$$
\left[\mathrm{Na}_{0.8}\right]^{\text {inter }}\left[\mathrm{Mg}_{2 \cdot 2} \mathrm{Li}_{0.8}\right]^{\text {oct }}\left[\mathrm{Si}_{4}\right]^{\text {tet }} \mathrm{O}_{10}(\mathrm{OH})_{2} \cdot x \mathrm{H}_{2} \mathrm{O},
$$

where $x$ is the number of water molecules per cation.

The XRD analyses were carried out on a Brüker D8advance using $\mathrm{Cu}-\mathrm{K} \alpha$ radiation. Data were recorded in the range of $5-35^{\circ} 2 \theta$ with a step of $0.02^{\circ} 2 \theta$ and a counting time of $80 \mathrm{~s} /$ step under controlled relative humidity (RH). Experimental XRD patterns were recorded at relative humidity (RH) conditions between $10 \%$ and $\sim 90 \%$. For each sample, XRD patterns were recorded following the same sequence of RHs, starting first from $35 \%$ (room) to $90 \%$ and then reducing $\mathrm{RH}$ down to $20 \%$ and $10 \%$.

The mineralogical and structural characteristics were determined by comparing the experimental X-ray patterns with the theoretical patterns calculated from structural models (Pons et al 1995; Drits and Tchoubar 1990) and permits determination of the number and position of the intercalated water molecules. XRD patterns were calculated using the $z$-coordinates, where the origin of the atomic coordinates was taken at the basal oxygen atoms (Karmous et al 2009). The diffracted intensity for a unit-cell along the 00 rod of the reciprocal space is given by the following expression developed by Ben Haj Amara et al (1998):

$$
I_{00}(2 \theta)=L_{\mathrm{p}} \operatorname{Spur}\left(\operatorname{Re}[\phi][W]\left\{[I]+2 \sum_{n}^{M-1}[(M-n) / M][Q]^{n}\right\}\right) \text {, }
$$

\footnotetext{
*Author for correspondence (karmousssalah@yahoo.fr)
} 
with $L_{\mathrm{p}}=\psi \frac{1+\cos ^{2} 2 \theta}{\sin 2 \theta}$, where $\Psi$ is the orientation factor of the particles, Re the real part of the final matrix, Spur, the sum of the diagonal terms of the real matrix; $M$, the number of layers per stack; $n$, an integer varying between 1 and $M-1$; $[\Phi]$, the structure factor matrix $[I]$, the unit matrix $[W]$, the diagonal matrix of the proportions of the different kinds of layers, and $[Q]$ the matrix representing the interference phenomena between adjacent layers. For a system made up of two types of layers $(A$ and $B$ ) and a nearest neighbour interaction, $[Q]$ takes the form

$$
\operatorname{det} Q=\left|\begin{array}{ll}
P_{\mathrm{AA}} \exp \left(-2 i \pi s d_{\mathrm{A}}\right) & P_{\mathrm{AB}} \exp \left(-2 i \pi s d_{\mathrm{A}}\right) \\
P_{\mathrm{BA}} \exp \left(-2 i \pi s d_{\mathrm{B}}\right) & P_{\mathrm{BB}} \exp \left(-2 i \pi s d_{\mathrm{B}}\right)
\end{array}\right|,
$$

where $s$ is the modulus of the scattering vector; $s=\frac{2 \sin \theta}{\lambda}$, $d_{\mathrm{A}}$ and $d_{\mathrm{B}}$ are the $d$-spacing of layers $A$ and $B$, respectively and $P_{\mathrm{AB}}$ the conditional probability of passing from layer $A$ to layer $B$. The relationship between different kinds of layer proportions and probabilities are given by

$$
\begin{aligned}
& W_{\mathrm{A}}+W_{\mathrm{B}}=1, P_{\mathrm{AA}}+P_{\mathrm{AB}}=1, P_{\mathrm{BA}}+P_{\mathrm{BB}}=1 \\
& \text { and } W_{\mathrm{A}} P_{\mathrm{AB}}=W_{\mathrm{B}} P_{\mathrm{AB}} .
\end{aligned}
$$

The overall fit quality was assessed using the unweighted $R_{\mathrm{p}}$ parameter (Howard and Preston 1989)

$$
R_{\mathrm{p}}=\sqrt{\frac{\sum\left[I_{\mathrm{obs}}\left(2 \theta_{i}\right)-I_{\mathrm{calc}}\left(2 \theta_{i}\right)\right]^{2}}{\sum I_{\mathrm{obs}}\left(2 \theta_{i}\right)^{2}}},
$$

where $I_{\mathrm{obs}}$ and $I_{\text {calc }}$ represent, respectively measured and calculated intensities, at position $2 \theta_{i}$, the subscript $i$ running over all points in the refined angular range. This parameter is mainly influenced by the most intense diffraction maxima, such as the $00 l$ reflection, which contains essential information on the proportions of the different layer types and on their layer thickness.
The structural characteristics along the normal to the layer plane $(z)$ were determined by comparing the experimental $\mathrm{X}$-ray patterns with theoretical ones calculated from structural models; by fitting positions and profiles of the $00 l$ reflections over a large angular range, the relative proportions of the different layer types can be determined together with the thickness and water content of the different layer types (Karmous et al 2009).

\section{Results and discussion}

The hydration state of smectites has been described using four layer types of different layer thicknesses and corresponding to the most common hydration states reported for smectites in non-saturated conditions: dehydrated layers ( $0 \mathrm{~W}$, layer thickness $\sim 9 \cdot 6-10 \cdot 1 \AA$ ), monohydrated layers ( $1 \mathrm{~W}$, layer thickness $\sim 12 \cdot 3-12.7 \AA$ ), and bi-hydrated layers ( $2 \mathrm{~W}$, layer thickness $\sim 15 \cdot 1-15 \cdot 8 \AA$ ) and trihydrated (3 W, layer thickness $\sim 18-19 \AA$ ) layers, the latter being less common (Ferrage et al 2005a,b). However, it was soon recognized that different hydration states/layer types usually coexist even under controlled conditions due to structural heterogeneities affecting the layer charge distribution (from one interlayer to the other or within a given interlayer) and/or location. Such a coexistence is for instance revealed by the irrationality of the $00 \mathrm{l}$ reflection series and by peak profile asymmetry at the transition between two hydration states (Karmous et al 2009).

The XRD patterns of $\mathrm{Ca}$ saponite recorded at relative humidity between 20 and $80 \%$ are shown in figure 1 . The qualitative study shows that it is characterized by asymmetrical $00 l$ reflections and a $d_{001}$ spacing of 12.91 to $13.58 \AA$ for $\mathrm{RH}$ rates $\leq 40 \%$ (figures $1 \mathrm{a}$ and $\mathrm{b}$ ), this corresponds to heterogeneous hydration state with different layer types ( $1 \mathrm{~W}$ and $2 \mathrm{~W})$. At $60 \% \mathrm{RH}$, the $00 l$ reflection is at $15.74 \AA$ indicating

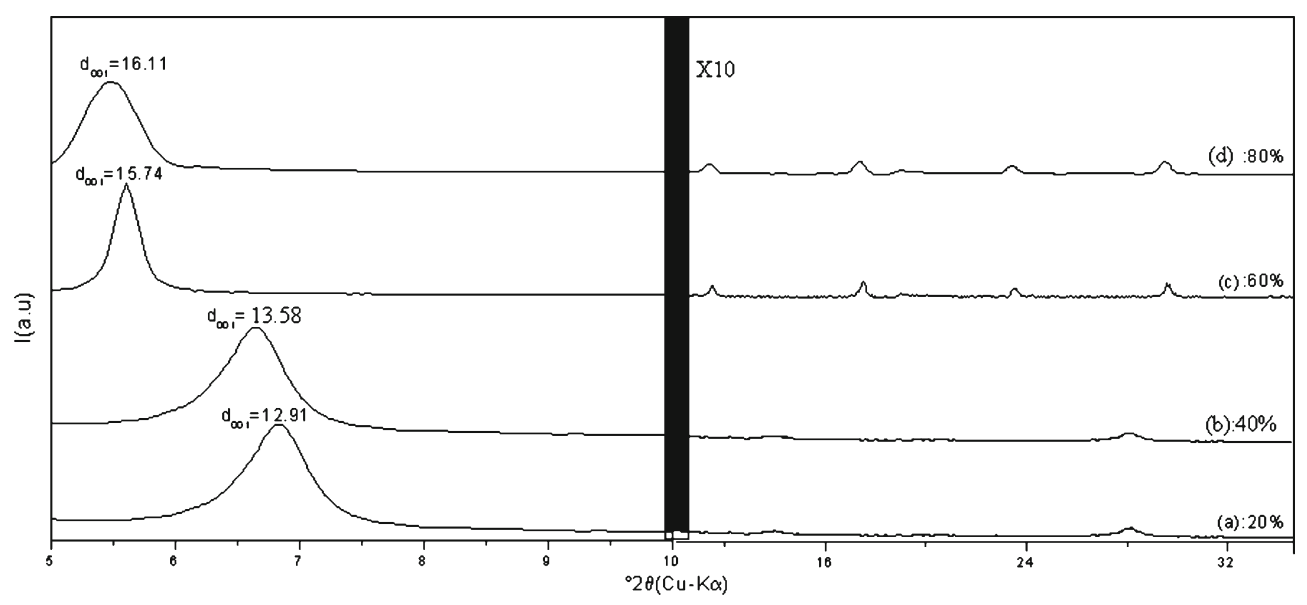

Figure 1. Experimental patterns of Ca-saponite recorded at different RH. 
Table 1. Ca-saponite structural parameters deduced from XRD simulation $\left(n\left(\mathrm{H}_{2} \mathrm{O}\right)\right.$; number of water molecule; $\mathrm{Z}\left(\mathrm{H}_{2} \mathrm{O}\right)$; position of water molecule along $c^{*}$ axis and $W$ is abundance of water hydration state (per half unit cell)).

\begin{tabular}{|c|c|c|c|c|}
\hline $\mathrm{RH}(\%)$ & & $20-40$ & $40-60$ & $60-90$ \\
\hline \multirow[t]{4}{*}{$0 W$} & $d_{001}$ & $10 \AA$ & - & - \\
\hline & W & $0 \cdot 12$ & - & - \\
\hline & $n\left(\mathrm{H}_{2} \mathrm{O}\right)$ & - & - & - \\
\hline & $\mathrm{Z}\left(\mathrm{H}_{2} \mathrm{O}\right)$ & - & - & - \\
\hline \multirow[t]{4}{*}{$1 W$} & $d_{001}$ & $12.6 \AA$ & $12 \cdot 6 \AA$ & - \\
\hline & W & $0 \cdot 88$ & $0 \cdot 6$ & - \\
\hline & $n\left(\mathrm{H}_{2} \mathrm{O}\right)$ & $2 \cdot 4$ & $2 \cdot 4$ & - \\
\hline & $Z\left(\mathrm{H}_{2} \mathrm{O}\right)$ & $9.4 \AA$ & $9.4 \AA$ & - \\
\hline \multirow[t]{4}{*}{$2 W$} & $d_{001}$ & - & $15 \cdot 6 \AA$ & $15 \cdot 6 \AA$ \\
\hline & W & - & 0.4 & 0.83 \\
\hline & $n\left(\mathrm{H}_{2} \mathrm{O}\right)$ & - & $3 \cdot 2$ & $3 \cdot 2$ \\
\hline & $\mathrm{Z}\left(\mathrm{H}_{2} \mathrm{O}\right)$ & - & $15 \cdot 2-9 \AA$ & $15 \cdot 2-9 \AA$ \\
\hline \multirow[t]{4}{*}{$3 W$} & $d_{001}$ & - & - & $18.6 \AA$ \\
\hline & W & - & - & $0 \cdot 17$ \\
\hline & $n\left(\mathrm{H}_{2} \mathrm{O}\right)$ & - & - & 4 \\
\hline & $\mathrm{Z}\left(\mathrm{H}_{2} \mathrm{O}\right)$ & - & - & $18-15-12 \AA$ \\
\hline Layer number & & 11 & 12 & 10 \\
\hline Succession law & & Random & Random & Random \\
\hline
\end{tabular}

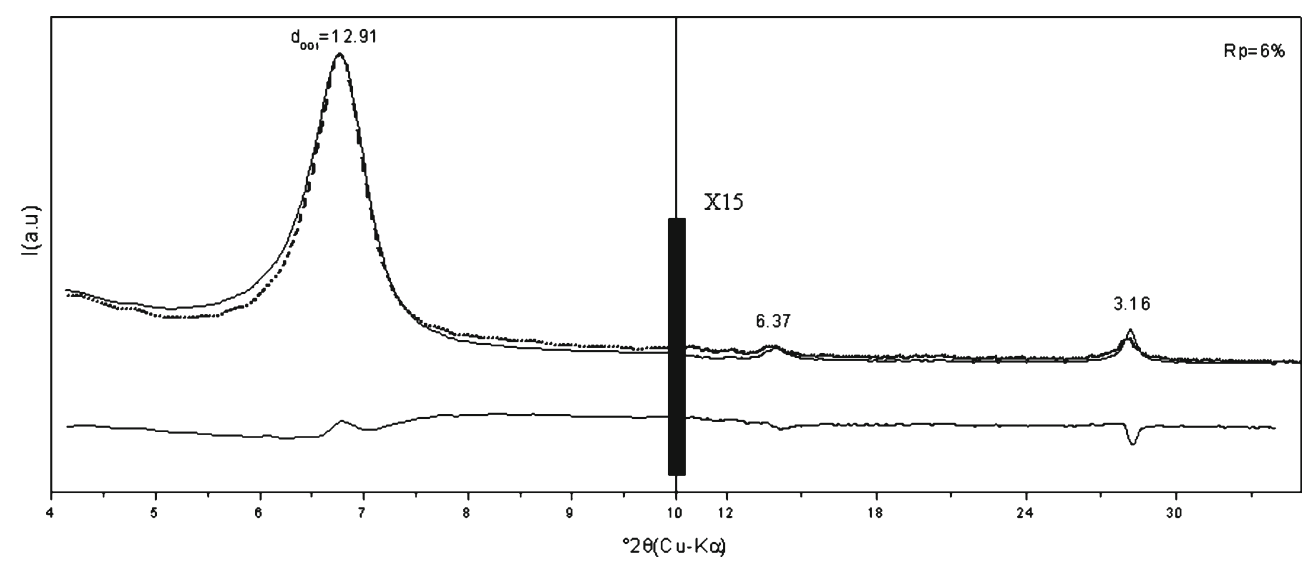

Figure 2. Best agreement between theoretical (-) and experimental (- - -) patterns of Ca-saponite at $\mathrm{RH}=40 \% ;(*)$ represents difference between theoretical and experimental patterns.

a total transition to $2 \mathrm{~W}$ state and vanishing of $1 \mathrm{~W}$ hydration state. For higher RH $(80 \%), d_{001}$ appears at $16 \cdot 11 \AA$ indicating the presence of $3 \mathrm{~W}$.

The quantitative study of XRD patterns allowed us to determine some structural parameters such as abundance, probabilities of each hydration state, number of layers, number and position of water molecules along the $z$ axis. These parameters at different $\mathrm{RH}$ are shown in table 1.

Calculated and experimental profiles of Ca-saponite are shown as a function of relative humidity together with their difference plots in figures 2, 3 .

Simulation of Ca-saponite XRD pattern (figure 2) shows that the best agreement between experimental and calculated plots is obtained with $R_{\mathrm{p}}$ equal to $6 \%$ with $88 \%$ of $1 \mathrm{~W}$ and $12 \%$ of $2 \mathrm{~W}$ randomly distributed, the average number of layer is 11 .

At high relative humidity, the interlayer space is characterized by the presence of $17 \%$ of $3 \mathrm{~W}$ and $83 \%$ of $2 \mathrm{~W}$ (figure 3 ) with reliability factor equal to $4 \%$.

All structural parameters deduced from simulation are presented in table 1 .

Comparing these results with those found for Ca-saponite with 0.4 charges per half unit cell (Karmous et al 2009), we can conclude that increasing layer charge leads to the formation of a more structured water and shifts hydration transitions toward lower relative humidity conditions. 


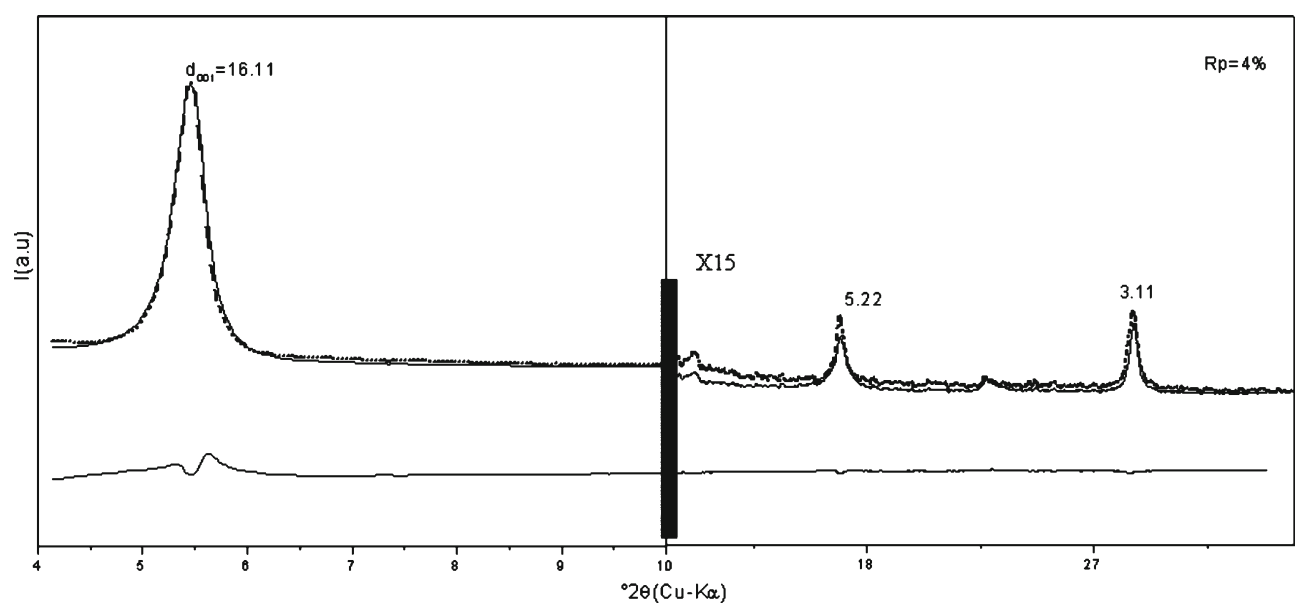

Figure 3. Best agreement between theoretical (-) and experimental (- - -) patterns of Ca-saponite at $\mathrm{RH}=80 \% ;(*)$ represents difference between theoretical and experimental patterns.

\section{Conclusions}

This study showed systematic hydration heterogeneity whatever the relative humidity (RH) and Ca-saponite sample presents many hydration states in whatever RH range. In all structural models the hydration states were randomly distributed in the interlayer space.

\section{References}

Ben Haj Amara A, Ben Brahim J, Plançon A and Ben Rhaiem H 1998 J. Appl. Crystallogr. 31654

Drits V A and Tchoubar C 1990 X-ray diffraction by disordered lamellar structures: Theory and application to microdivided silicates and carbons (New York: Springer)

Ferrage E, Lanson B, Malikova N, Plançon A, Sakharov B A and Drits V A 2005a Chem. Mater. 173499
Ferrage E, Lanson B, Sakharov B A and Drits V A 2005b Am. Mineral. 901358

Ferrage E, Lanson B, Michot L J and Robert J L 2010 J. Phys. Chem. C114 4515

Güven N 1988 Hydrous phyllosilicates (exclusive of micas) (ed.) S W Bailey (Washington D.C.: Mineralogical Society of America)

Howard S A and Preston K D 1989 Rev. Mineral. 20217

Karmous M S, Ben Rhaiem H, Naamen S, Oueslati W and Ben Haj Amara A 2006 Z. Kristallogr. Suppl. 23431

Karmous M S, Oueslati W, Ben Rhaiem H, Robert J L and Ben Haj Amara A 2007 Z. Kristallogr. Suppl. 26503

Karmous M S, Ben Rhaiem H, Robert J L, Lanson B and Ben Haj Amara A 2009 Appl. Clay Sci. 4634

Laird D A 2006 Appl. Clay Sci. 3474

Mooney R W, Keenan A G and Wood L A J 1952 J. Am. Chem. Soc. 741371

Pons C H, De la calle C and de Vidales M 1995 Clays Clay Miner. 43246 